\title{
A PERFORATED PLATE STACKED SI/GLASS HEAT EXCHANGER WITH IN-SITU TEMPERATURE SENSING FOR JOULE-THOMSON COOLERS
}

\author{
Weibin Zhu ${ }^{1 *}$, Michael J. White ${ }^{2}$, Gregory F. Nellis ${ }^{2}$, Sanford A. Klein ${ }^{2}$, Yogesh B. Gianchandani ${ }^{l}$ \\ ${ }^{1}$ Department of Mechanical Engineering, University of Michigan, Ann Arbor, USA \\ ${ }^{2}$ Department of Mechanical Engineering, University of Wisconsin, Madison, USA
}

\begin{abstract}
This paper reports a micromachined recuperative heat exchanger integrated with in-situ temperature sensors. In this design, numerous high-conductivity silicon plates, integrated with platinum resistance temperature detectors (Pt RTDs) are fabricated and stacked alternating with lowconductivity Pyrex spacers. The device is intended for use with Joule-Thomson (J-T) coolers. The fabricated versions of the device have a footprint of $1 \times 1 \mathrm{~cm}^{2}$, and lengths of up to $2 \mathrm{~cm}$. Tests at cryogenic temperatures $(120-210 \mathrm{~K})$ show that the effectiveness of the heat exchanger is as high as 0.785. In a preliminary $\mathrm{J}$ - $\mathrm{T}$ self-cooling test, the temperature at the expansion orifice dropped $13 \mathrm{~K}$ from the inlet temperature for an inlet pressure of $527 \mathrm{kPa}$ (76 psia). The integrated Pt RTDs presented a sensitivity of $0.26 \% / \mathrm{K}$ in the linear operational range of 150-300 K, but remained usable at temperatures below that range. Details regarding evaluation apparatus are discussed.
\end{abstract}

\section{INTRODUCTION}

The Joule-Thomson (J-T) cooling cycle has applications ranging from cryosurgery [1-2] to cooling detectors in space applications. In the J-T cycle, cold, highpressure fluid leaving a recuperative heat exchanger expands through a valve, resulting in a temperature drop through the valve if the state of the fluid lies below the inversion curve before expansion. With the absence of cold moving parts and the consequent potential for high reliability, the J-T cycle can be implemented with simple structures that are suitable for silicon/glass microfabrication.

In particular, we are interested in miniaturization of its recuperative heat exchanger component, which must maintain good stream-to-stream heat conductance between the high- and low-pressure streams while restricting streamwise conduction in order to allow a large enthalpy difference between the two streams. Microstructures inside the micromachined heat exchanger can significantly increase the heat transfer surface area and thus achieve higher efficiency than conventional heat exchangers with the same volume. Prior efforts of miniaturizing heat exchangers have used a concentric arrangement of commercial glass tubes [3], flexible polyimide heat exchangers [4], and planar Si/glass micromachined channels [5]. This paper describes results for a perforated-plate stacked Si/glass heat exchanger, designed for superior heat exchanger effectiveness, higher mass flow rate, and increased robustness.
In conventional J-T cooling instruments, which are made of stainless steel and oxygen-free high conductivity (OFHC) copper, it is difficult to insert discrete temperature sensors into the heat exchanger. One of the problems arises from sealing, because of the high pressure and low temperature requirements in $\mathrm{J}-\mathrm{T}$ cycle. Therefore, precise temperature measurement and thermal analysis inside the heat exchanger are challenging. In our micromachined perforated plate stacked heat exchanger, temperature sensors can be easily integrated into the Si/glass structure during the microfabrication process. The in-situ temperature sensing technique allows us to monitor the temperature distribution inside the heat exchanger and therefore, accurately validate our theoretical model as well as control the cooling process.

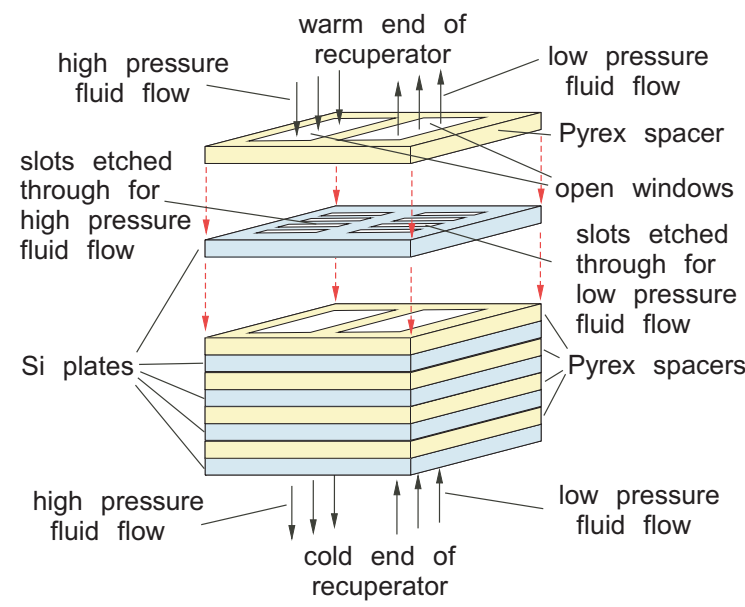

Fig.1: Perforated plate heat exchanger design (Pt RTDs not included). High-pressure fluid obtained from external compressor passes through a counter flow recuperative heat exchanger, where it is pre-cooled by the low-pressure fluid returning from the refrigeration load. The cold high-pressure fluid leaving the heat exchanger expands through a valve. The cold, low-pressure fluid is directed through the load heat exchanger where it is warmed by the refrigeration load and then is fed back into the heat exchanger.

\section{DESIGN \& FABRICATION}

In order to maintain good stream-to-stream heat conductance between the high- and low-pressure channels while restricting stream-wise conduction inside the heat exchanger, it is essential to select materials that have proper thermal properties and are compatible to the microfabrication process. Fortunately, the thermal properties of silicon and Pyrex, respectively, are reasonable substitutes for those of OFHC copper and stainless steel, and motivate the use of these materials for a micromachined heat exchanger.

\footnotetext{
"Corresponding author: 1301 Beal Ave., Ann Arbor, MI, 48109, USA; Tel: (734) 763-5914, Fax: (734) 763-9324. E-mail: zhuwb@umich.edu
} 


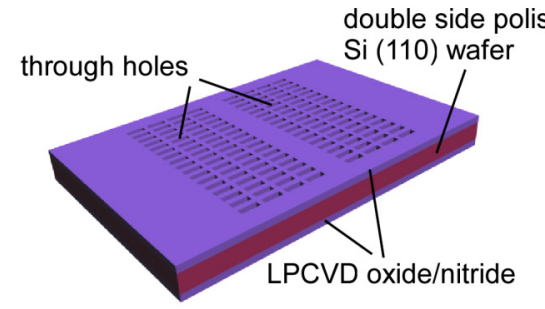

(1) Oxide/nitride mask are deposited and patterned by RIE. Si wafer is etched though in $\mathrm{KOH}$, oxide /nitride mask is then removed.

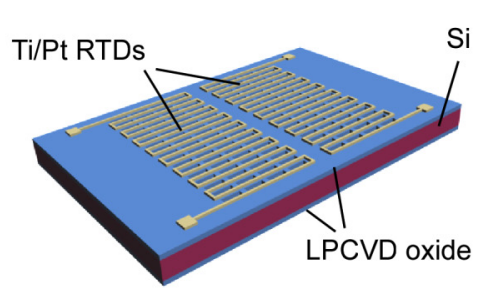

(2) LPCVD oxide is deposted, then Ti/Pt RTDs are patterned on the oxide layer.

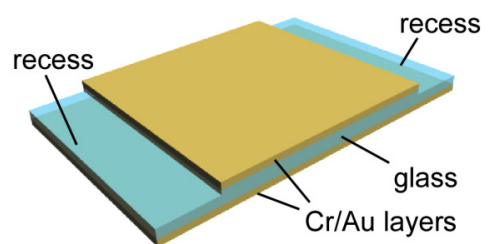

(3) $\mathrm{Cr} / \mathrm{Au}$ layers are deposited on both sides. $\mathrm{Cr} / \mathrm{Au}$ layer on the top is patterned, glass recess is etched down 20 microns.

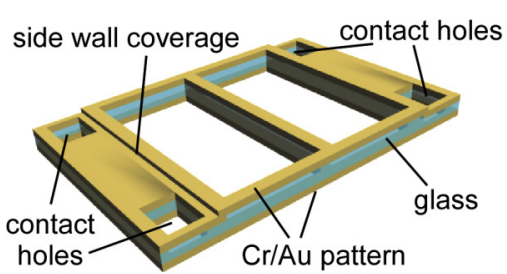

(4) A new $\mathrm{Cr} / \mathrm{Au}$ layer is sputtered on the top side. Etch through glass wafer from both sides in $\mathrm{HF}: \mathrm{HNO}_{3}, \mathrm{Cr} / \mathrm{Au}$ layers are then removed.

Fig. 2: Fabrication process of the perforated plate Si/glass heat exchanger with Pt RTDs

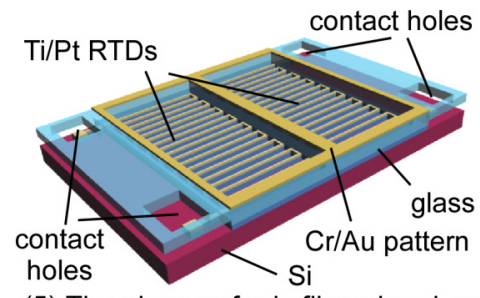

(5) The glass wafer is flipped and anodically bonded to the Si wafer. Oxide layer is then removed in BHF. $\mathrm{Cr} / \mathrm{Au}$ layer is patterned on the top of glass for $\mathrm{Si}-\mathrm{Au}$ eutectic bonding.

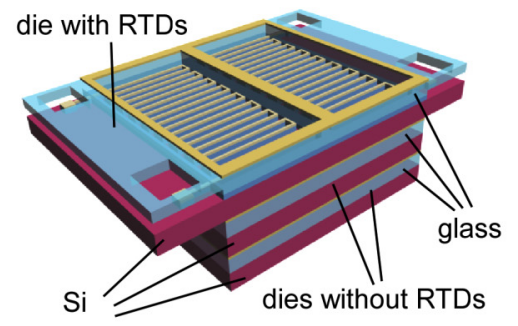

(6) The wafer is diced. Dies are stacked and $\mathrm{Si}-\mathrm{Au}$ eutectic bonded together.
The perforated plate stacked Si/glass heat exchanger (Fig. 1) uses numerous high-conductivity silicon plates alternating with low-conductivity Pyrex glass spacers. Narrow slots are etched into the Si plate in order to provide two sets of passages that are characterized by a large heat transfer surface area. Each plate is divided into two isolated regions. The high and low pressure regions are sealed from each other by the joint between the $\mathrm{Si}$ plates and glass spacers. The heat from the high pressure fluid into the silicon plate is conducted through the silicon plate into the low pressure region where it is finally transferred to the low pressure fluid. The geometric details of this design, including number and size of the slots, distance between slots, number of plates, etc., have been numerically optimized [6]. Dies integrated with Pt RTDs can be

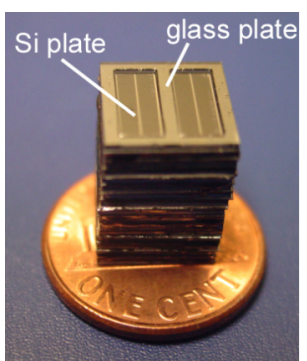

a)

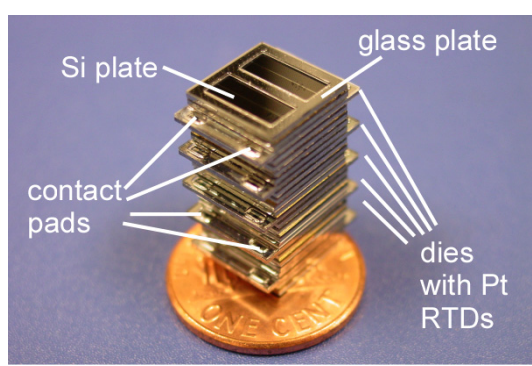

b)
Fig. 3: The die size of perforated plate micro heat exchanger is $1 \times 1$ $\mathrm{cm}^{2}$. The thickness of Si plate in each die is $500 \mu \mathrm{m}$. The thickness of Pyrex spacer is $300 \mu \mathrm{m}$. Two rows of opening slots are on both high pressure and low pressure sides on Si plate. The slot is $50 \mu \mathrm{m}$ wide and $1400 \mu \mathrm{m}$ long; there is $50 \mu \mathrm{m}$ gap between each slot. a) Heat exchanger (without Pt RTD) boned by STYCAST 2850FT epoxy. The total length is about $1.2 \mathrm{~cm}(15$ dies). b) Heat exchanger (with Pt RTDs) fabricated by $\mathrm{Si}-\mathrm{Au}$ eutectic bonding. The Dies with Pt RTDs are equally distributed across the entire length of the micro heat exchanger. The total length is about $2 \mathrm{~cm}$ ( 25 dies). selectively bonded to the heat exchanger in order to allow precise and real-time measurement of the temperature distribution inside the heat exchanger.

A four-mask fabrication process for this heat exchanger (Fig. 2) uses $\mathrm{KOH}$ wet-etching of (110) Si to obtain vertical sidewalls in the slots, and $\mathrm{HF}: \mathrm{HNO}_{3}$ wet etching of Pyrex wafers to fabricate windows. Thin film $\mathrm{Ti} / \mathrm{Pt}$ is deposited and patterned (in a lift-off process) on a $100-\mathrm{nm}$ thick $\mathrm{SiO}_{2}$ insulation layer to form Pt RTDs on the Si substrate. Dies without thin film Pt RTD are also fabricated in the same process by masking $\mathrm{Ti} / \mathrm{Pt}$ deposition with a photoresist layer (in the same lift-off process). Two different methods are used for bonding the Si/glass stack: 1) Epoxy STYCAST 2850FT (Emerson \& Cuming, Inc., Billerica, MA, USA) is used to bond Si/glass individually [7]. Figure 3a shows a fabricated $1 \times 1 \mathrm{~cm}^{2}$ heat exchanger with 15 dies (without $\mathrm{Pt}$ RTD) bonded by epoxy. 2) $\mathrm{Si}$-Au eutectic bonding is used to simultaneously bond the Si/glass heat exchanger stack. This avoids the tedious procedure of bonding $\mathrm{Si} /$ glass dies separately. A $1 \times 1 \mathrm{~cm}^{2}$ heat exchanger (25 dies) integrated with Pt RTDs fabricated by Si-Au bonding is shown in Fig. $3 b$.

\section{EXPERIMENTAL SETUP}

A macro-scale test facility was developed; the flow schematic of this system is shown in Figure 4. An external compressor is interfaced with the test facility in order to allow a closed loop cycle, and therefore, provide continuous test data. The system was designed for two different experiments: 1) In the applied cooling mode, an external cryocooler and a heater are used to control large temperature differences across the heat exchanger with minimal pressure differences inside. The jewel orifice is replaced by a solid piece (and therefore, flow through the path labeled jewel orifice is shut off) and the inlet pressure from the 
compressor is kept low $(120-260 \mathrm{kPa})$. The fluid leaving the heat exchanger flows along the dashed arrows in Fig. 4 and is cooled down to cryogenic temperature by the external cryocooler. Helium is used in this mode. The large temperature differences produced by the external cryocooler enable the effectiveness of the heat exchanger to be accurately measured. 2) In the self-cooling mode, the flow path to the external cryocooler is closed and a jewel orifice is installed, allowing flow through a very small opening which provides the pressure drop and J-T effect. The fluid flows along the solid arrows in Fig. 4. The heat exchanger is thus used in a J-T cycle. The inlet pressure is adjusted by the external compressor.

In either mode, temperatures and pressures at the highpressure inlet (of heat exchanger), high-pressure outlet, lowpressure inlet and low-pressure outlet are measured (respectively denoted in Fig. 4 by subscripts 1, 2, 3, and 4).

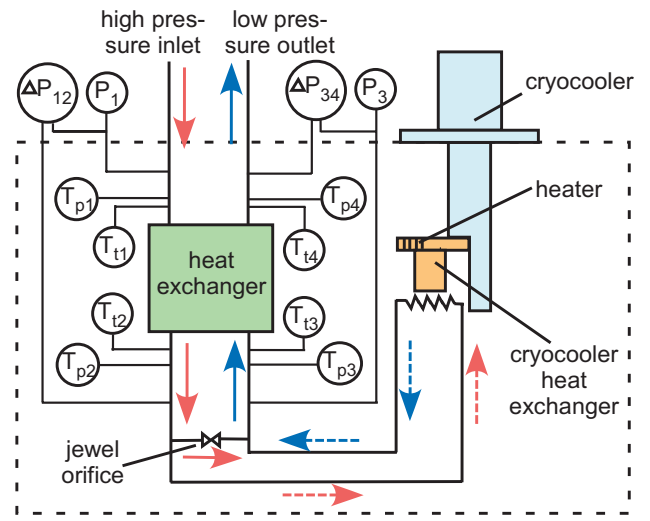

Fig. 4: Flow schematic of components inside the test apparatus. In applied cooling mode, fluid flow along the dashed arrows when jewel orifice is closed. Helium gas is used in this mode. $\Delta \mathrm{P}_{12}=\mathrm{P}_{1^{-}}$$\mathrm{P}_{2} ; \Delta \mathrm{P}_{34}=\mathrm{P}_{3}-\mathrm{P}_{4}$.

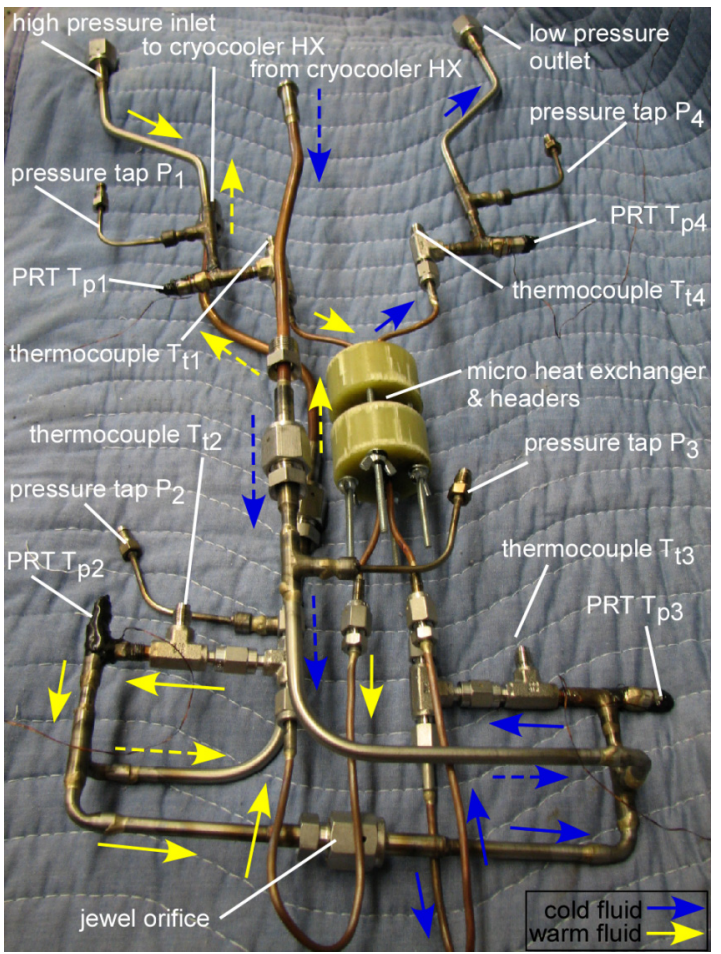

Fig.5: Instruments inside the test facility
Two sets of temperature measurements are recorded simultaneously: A) commercially available platinum resistance thermometers (PRTs), denoted by $\mathrm{T}_{\mathrm{p}} ; \mathrm{B}$ ) thermocouples, denoted by $T_{t}$. The mass flow rate of the heat exchanger is measured and the effectiveness is calculated [7]. The effectiveness of the heat exchanger is defined as the ratio of the heat transferred within the heat exchanger to the maximum possible amount of heat that could have been transferred had the heat exchanger been perfect (i.e., the heat transferred if $\mathrm{T}_{4}$ was equal to $\mathrm{T}_{1}$ ).

Figure 5 shows the instruments inside the test facility. The heat exchanger was mounted to the G-10 headers with STYCAST 2850FT epoxy and then the whole assembly was installed to the system. Helium leak tests were performed before and after the installation.

\section{EXPERIMENTAL RESULTS}

The epoxy-bonded short stack heat exchanger (Fig. 3a) with $1 \times 1 \mathrm{~cm}^{2}$ cross section and 15 dies $(1.2 \mathrm{~cm}$ long) was installed and tested in the facility mentioned in the previous section. All of the temperature measurement data shown in the plots in this section were recorded from a set of thermocouples. The temperature reading of the PRTs was also taken during the experiments and these measurements agree with the thermocouple reading to within experimental uncertainty.

Figure 6 shows the measured effectiveness of the heat exchanger as the flow rate is changed in applied cooling mode. The experiments were completed at cryogenic temperature range of $120-210 \mathrm{~K}$. The maximum measured effectiveness of the heat exchanger was 0.785 at $0.0344 \mathrm{~g} / \mathrm{s}$ helium mass flow rate. We expect that the measured effectiveness was lower than the simulation estimate in the range of measured flow rate mainly due to the following reasons: a) stream-to-stream leakage inside heat exchanger or headers; b) parasitic heat loads; c) clogging inside the heat exchanger due to impurities freezing out of the helium. Further thermal insulation and a cold trap to filter out impurities could be added to improve the accuracy of the measurements.

A preliminary test was necessary to determine the optimal size of the expansion orifice in self-cooling mode.

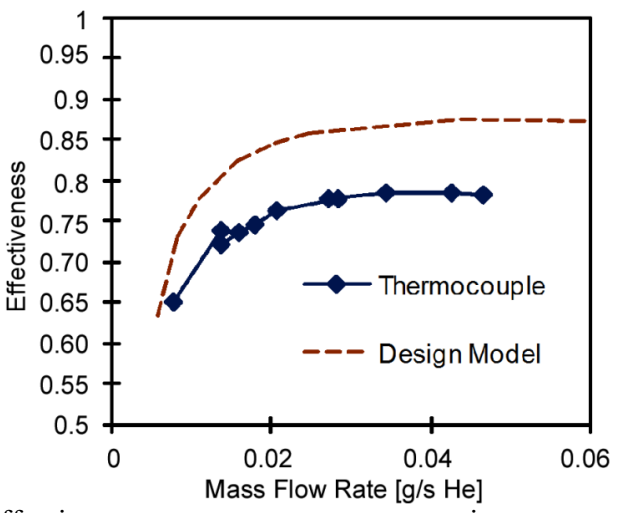

Fig. 6: Effectiveness measurement at cryogenic temperature range (120-210 K). Two independent sets of data are measured from thermocouples and PRTs. The effectiveness is defined as $\left(\mathrm{T}_{1^{-}}\right.$ $\left.\mathrm{T}_{2}\right) /\left(\mathrm{T}_{1}-\mathrm{T}_{3}\right)$. 
Figure 7 shows this test result from a simple test setup without vacuum insulation. Instead of using the external compressor in the self-cooling test (Fig. 4), compressed gas was introduced to the inlet of the system and gas from the outlet was vented. Experiment results showed that the best orifice size was $0.2 \mathrm{~mm}^{2}$. The heat exchanger was then tested inside the test facility (with the external compressor) in the self-cooling mode at much higher pressure. Ethane gas was used in this test. The orifice size was $0.2 \mathrm{~mm}^{2}$. Figure 8 shows the measured temperature drop at the orifice

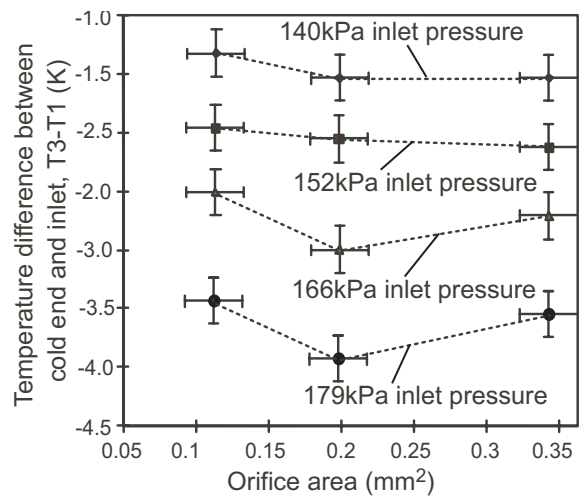

Fig. 7: The temperature difference between inlet and cold end is $\Delta \mathrm{T}=\mathrm{T}_{3}-\mathrm{T}_{1}$, where $\mathrm{T}_{1}$ is the inlet flow temperature, $\mathrm{T}_{3}$ is the temperature at the cold end. The self-cooling performance of the test setup is the best at an orifice size of $0.2 \mathrm{~mm}^{2}$.

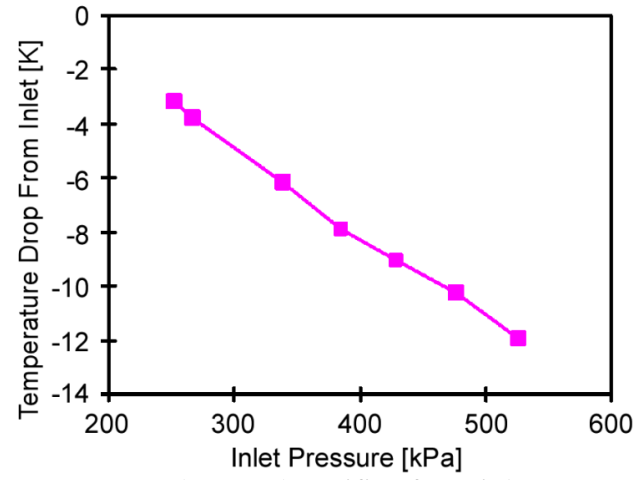

Fig. 8: Temperature drop at the orifice from inlet temperature as a function of inlet pressure in the self-cooling test. The orifice size used in this test is $0.2 \mathrm{~mm}^{2}$.

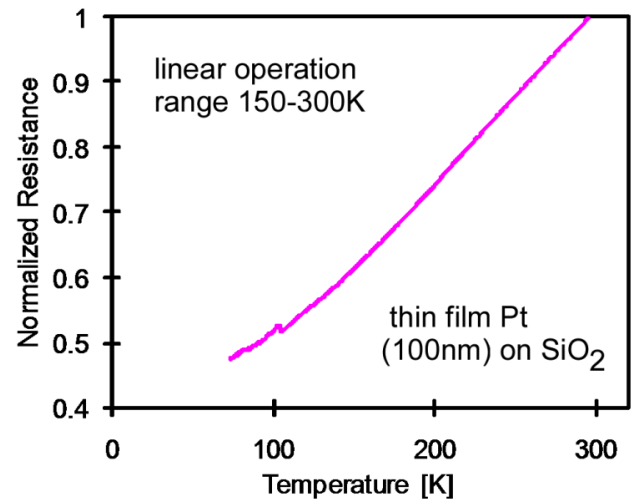

Fig. 9: Normalized resistance measurement of the Pt RTD in a $10 \mathrm{~mm}$ heat exchanger as a function of temperature of the thermocouple. The Pt RTDs are used for in-situ temperature sensing. The resistance at room temperature $(295.79 \mathrm{~K}$ from thermocouple) is $4.287 \mathrm{~K} \Omega$. The sensitivity is $0.26 \% / \mathrm{K}$. as a function of inlet pressure in the self-cooling test. The temperature dropped $13 \mathrm{~K}$ from inlet temperature as the inlet pressure was $527 \mathrm{kPa}$ (76 psia). The inlet pressure was not further increased in order to avoid damaging the heat exchanger. The heat exchanger and test facility remained leak tight after the experiments.

The Pt RTD for in-situ temperature sensing in the heat exchanger was tested with a PRT and a thermocouple at a temperature range of $80-300 \mathrm{~K}$. The RTD resistance and temperature measured by the PRT and thermocouple were simultaneously recorded in a Labview program. Figure 9 shows the normalized resistance as a function of temperature of the thermocouple. The plot from the PRT reading is almost identical to Fig. 9. The sensor has a sensitivity of $0.26 \% / \mathrm{K}$ in its linear range of $150-300 \mathrm{~K}$.

\section{CONCLUSION}

This effort has resulted in the successful fabrication of a micromachined perforated plate stacked Si/glass heat exchanger integrated with Pt RTDs. A multifunctional cryogenic test facility was built for comprehensive experiments of this heat exchanger. The heat exchanger demonstrated acceptable effectiveness in cryogenic temperature range and excellent robustness at high working pressures. Embedded temperature sensors showed consistent sensitivity across cryogenic temperature range at 150-300 K.

\section{ACKNOWLEDGEMENT}

The authors appreciate Mr. Daniel W. Hoch for his contribution to design and modeling of this work. The work was funded in part by a grant from the US National Institutes of Health (R33 EB003349-05).

\section{REFERENCES}

[1] J. Dobak, "A Review of Cryobiology and Cryosurgery," Advances in Cryogenic Engineering, 43, pp. 889-896, 1998.

[2] E.D. Marquardt, et al., "A Cryogenic Catheter for Treating Heart Arrhythmia," Advances in Cryogenic Engineering, 43, pp. 903-910, 1998.

[3] J. Burger, et al., "169 Kelvin Cryogenic Microcooler Employing a Condenser, Evaporator, Flow Restriction and Counterflow Heat Exchangers" Proc. IEEE MEMS, pp. 418-421, 2001.

[4] J.C. Selby, M.L. Philpott, M.A. Shannon, "Fabrication of Mesoscopic, Flexible, High Pressure, Microchannel Heat Exchangers (MHEx)," Trans of NAMRI/SME, Vol. 29, pp. 469-476, 2001.

[5] W. Zhu, D.W. Hoch, G.F. Nellis, S.A. Klein, Y.B. Gianchandani, "A Planar Glass/Si Micromachining Process for the Heat Exchanger in a J-T Cryosurgical Probe," Proc. Solid State Sensors, Actuators and Microsystems Workshop, Hilton Head, pp.51-55, 2006.

[6] D. W. Hoch, et al., "Progress Towards a Micromachined Heat Exchanger for a Cryosurgical Probe," Proc. the 14th International Cryocoolers Conference, Annapolis, Maryland, 2006.

[7] W. Zhu, M.J. White, D.W. Hoch, G.F. Nellis, S.A. Klein, Y.B. Gianchandani, "Two Approaches to Micromachining Si Heat Exchangers for Joule-Thomson Cryosurgical Probes," Proc. IEEE MEMS, Kobe, Japan, pp. 317-320, 2007. 